\title{
Comparação da Quantidade de Células de Langerhans em Neoplasias Intraepiteliais Cervicais e Cervicites Crônicas
}

doi: https://doi.org/10.32635/2176-9745.RBC.2019v65n2.65

\author{
Comparison of the Quantity of Langerhans Cells in Cervical Intraepithelial Neoplasia and Chronic Cervicitis \\ Comparación de la Cantidad de Células de Langerhans en Neoplasias Intraepiteliales Cervicales y Cervicites Crónicas
}

\author{
Júlia Tavares Lopes'; Marcella Castro²; Luiz Martins Collaço³
}

Resumo

Introduçáo: O câncer cervical é atribuído ao papilomavírus humano (HPV) cuja infecção, na maioria das vezes, sofre regressão espontânea. A menor porção de casos que evoluem para lesão precursora de baixo e alto graus e invasora pode ter relação com uma falha na atividade das células de Langerhans em eliminar o vírus. Objetivo: Determinar se há redução do número de células de Langerhans em colos uterinos acometidos por neoplasias intraepiteliais cervicais (NIC), graus I e III, comparado ao grupo controle (cervicites crônicas), por imuno-histoquímica, possibilitando correlacionar a ação do sistema imune com o desenvolvimento dessas lesões. Método: Foram analisados 40 casos de cervicite crônica, NIC I e III, com diagnóstico anatomopatológico entre janeiro de 2014 e dezembro de 2015 , buscando-se comparar a quantidade de núcleos marcados positivamente como célula de Langerhans pela proteína S-100 por imuno-histoquímica, quantificando-os em áreas padronizadas. Resultados: Dos 40 casos avaliados, 17 foram cervicite crônica, 13 NIC I e 10 NIC III. Na análise comparativa do número de células em cada grupo a média, desvio-padrão e mediana foram maiores no grupo cervicite crônica e menores no grupo NIC III. O valor de p encontrado para a variação do número de células de Langerhans, entre os grupos, foi significativo ( $\mathrm{p}=0,0442$ ); mas, ao comparar os grupos de NIC com o controle, só o grupo NIC III teve variaçáo significativa ( $\mathrm{p}=0,0209)$. Conclusáo: Há diminuição significativa do número de núcleos de células de Langerhans marcados em lesôes do tipo NIC III em comparação a cervicites crônicas.

Palavras-chaves: Neoplasia Intraepitelial Cervical; Células de Langerhans; Papillomaviridae; Carcinoma in Situ; Imuno-Histoquímica.

\section{Abstract}

Introduction: Cervical cancer is attributed to human papillomavirus (HPV), whose infection mostly undergoes spontaneous regression. The smaller part of cases that evolve to low and high-grade lesions or invasive lesions may be related to failure of Langerhans cell activity to eliminate the virus. Objective: To determine if there is reduction of Langerhans' cells in cervix uterus affected by cervical intraepithelial neoplasms (CIN) grades I and III compared to control group (chronic cervicitis) by immunohistochemistry, granting the correlation of the immune system action with the development of these lesions. Method: It were analyzed 40 cases of chronic cervicitis, CIN I and III with anatomopathological diagnosis between January 2014 and December 2015, attempting to compare the amount of positively labeled Langerhans cells nuclei by $S-100$ protein by immunohistochemistry, quantifying them in standard areas. Results: Of the 40 evaluated cases, 17 were chronic cervicitis, 13 CIN I and 10 CIN III. The comparative analysis of the number of cells in each group showed that the mean, standard deviation and median number of Langerhans cells per area were higher in the chronic cervicitis group and lower in the CIN III group. The $\mathrm{p}$ value found in the variation of the Langerhans cells number among the groups was significant $(\mathrm{p}=0.0442)$. However, when comparing the CIN groups directly with the control group, only the CIN III group had a significant variation $(p=0.0209)$. Conclusion: There is a significant decrease in the number of marked Langerhans cell nuclei in CIN III type lesions compared to chronic cervicitis.

Key words: Cervical Intraepithelial Neoplasia; Langerhans Cells; Papillomaviridae; Carcinoma in Situ; Immunohistochemistry.

\section{Resumen}

Introducción: El cáncer cervical puede atribuirse al virus del papiloma humano $(\mathrm{VPH})$ cuya infección a menudo sufre regresión espontánea. El menor número de casos que evolucionan a lesiones precursoras de bajo y alto grado o invasivas puede estar relacionado con una falla en la actividad de las células de Langerhans para eliminar el virus. Objetivo: Determinar si hay reducción del número de células de Langerhans en colos uterinos acometidos por neoplasias intraepiteliales cervicales (NIC) grados I y III comparado al grupo control (cervicitis crónicas), por medio de inmunohistoquímica, posibilitando correlacionar la acción del sistema inmune con estas lesiones. Método: Se analizaron 40 casos de cervicitis crónica, NIC I y III, con diagnóstico anatomopatológico entre enero de 2014 y diciembre de 2015, comparando la cantidad de núcleos marcados positivamente como célula de Langerhans por la proteína S-100 por inmuno-histoquímica, cuantificándolos. Resultados: De 40 casos, 17 fueron cervicitis crónica, 13 NIC I y 10 NIC III. En el análisis comparativo del número de células en cada grupo la media, desviación estándar y mediana fueron mayores en el grupo cervicite crónica y menores en el NIC III. El valor de p encontrado para la variación del número de células de Langerhans entre los grupos fue significativo ( $\mathrm{p}=0,0442)$, pero al comparar los grupos de NIC con el control sólo el grupo NIC III tuvo variación significativa ( $\mathrm{p}=0,0209)$. Conclusión: Hay disminución significativa del número de núcleos marcados de células de Langerhans en lesiones de tipo CIN III en comparación con cervicitis crónica.

Palabras clave: Neoplasia Intraepitelial Cervical, Células de Langerhans; Papillomaviridae; Carcinoma in Situ; Inmunohistoquímica.

\footnotetext{
${ }^{1}$ Faculdade Evangélica Mackenzie do Paraná (Fempar). Curitiba (PR), Brasil. Orcid iD: https://orcid.org/0000-0002-3215-1650

${ }^{2}$ Fempar. Curitiba (PR), Brasil. Orcid iD: https://orcid.org/0000-0002-8454-0447

${ }^{3}$ Fempar. Curitiba (PR), Brasil. Orcid iD: https://orcid.org/0000-0002-3215-1650

Endereço para correspondência: Luiz Martins Collaço. Rua Padre Anchieta, 2770 - Bigorrilho. Curitiba (PR), Brasil. CEP 80730-000. E-mail: Imcollaco@uol.com.br
} 


\section{INTRODUÇÃO}

O câncer cervical é uma doença extremamente prevalente e danosa, constituindo um problema de saúde pública. É o terceiro câncer mais frequente na população feminina e a quarta causa de morte de mulheres por câncer no Brasil ${ }^{1}$. Essa neoplasia é considerada prevenível e apresenta uma história natural já conhecida ${ }^{2}$.

Há inicialmente lesôes pré-cancerosas, as neoplasias intraepiteliais cervicais (NIC), que podem evoluir para carcinoma invasor ${ }^{3}$. As NIC podem ser classificadas de acordo com o grau de acometimento epitelial, NIC I, comprometendo as camadas basais; NIC II, acometendo até três quartos do epitélio; e NIC III, acometendo todas as suas camadas ${ }^{4}$.

O câncer cervical é o único reconhecido pela Organização Mundial da Saúde como totalmente atribuído a um agente infeccioso, o papilomavírus humano (HPV), um DNA vírus de transmissão majoritariamente sexual. A maior parte das infeções pelo HPV é eliminada com a ativação do sistema imune, mas algumas não regridem e evoluem para uma lesão intraepitelial cervical ou até para o câncer ${ }^{6}$. A alta taxa de regressáo espontânea junto com a pequena porcentagem de casos que acabam evoluindo para neoplasia indicam que apenas a infecção não é o suficiente ${ }^{7}$, é necessária uma falha na eliminação do vírus pelo sistema imune ${ }^{6}$.

As células de Langerhans são dendríticas apresentadoras de antígenos da pele e mucosas ${ }^{8}$ que atuam também nos mecanismos de defesa contra neoantígenos. Nas lesôes cervicais provocadas pelo HPV, a diminuição das células de Langerhans parece estar ligada ao seu grau de atipia?. A identificação e a determinação do número de células de Langerhans podem ser realizadas pela utilização de anticorpos direcionados às moléculas de superfície por imuno-histoquímica. Os anticorpos mais utilizados para essa finalidade são os anti-S-100, anti-Cd1a, anti-Cd83 e anti-Langerina ${ }^{5}$.

Este estudo objetiva determinar, na mucosa cervical, se há redução das células de Langerhans, por meio de marcação imuno-histoquímica com a proteína S-100, em epitélios acometidos por cervicite crônica (grupo controle), lesão de baixo grau (NIC I) e lesão de alto grau (NIC III), possibilitando correlacionar a açâo do sistema imune com o desenvolvimento ou não da neoplasia.

\section{MÉTODO}

Realizou-se um estudo observacional, descritivo, transversal. O material foi obtido no Laboratório de Anatomia Patológica do Hospital Universitário Evangélico Mackenzie de Curitiba, compreendendo o período de janeiro de 2014 a dezembro de 2015. Foram selecionados os casos de pacientes submetidas à histerectomia ou conização por cirurgia de alta frequência (CAF) nesse período.

A partir das lâminas histológicas revisadas, foram selecionadas e marcadas as regiôes contendo as lesóes relevantes para o estudo, as lâminas marcadas foram utilizadas para localização da mesma regiáo no bloco de parafina.

A partir dos blocos de parafina, foram confeccionados blocos multiamostrais (TMA), perfurando os blocos doadores na área amostral, obteve-se um cilindro de tecido que foi implantado no bloco receptor. Cada fragmento amostral retirado do bloco doador foi colocado no bloco receptor conforme um mapa tipo "plano cartesiano", totalizando 16 amostras de tecido em cada bloco de TMA.

Dos blocos de TMA, foram confeccionadas lâminas e, nelas, realizada a marcação por imuno-histoquímica com a proteína $S-100$. Posteriormente, as lâminas foram escaneadas no Scanner Axio Scan.Z1 e feita a avaliaçâo quantitativa das células, somente na camada epitelial, por meio de contagem dos núcleos marcados positivamente com morfologia para célula de Langerhans, utilizando-se o programa Zen 2.3 Lite $^{\circledR}$.

$\mathrm{Na}$ avaliação com o programa, foi realizada a contagem dos núcleos marcados positivamente no epitélio cervical, sempre na regiáo de marcação mais intensa, dentro de uma área circular de 37.507,089 $\mu \mathrm{m}$. Em razão da discrepância da área de tecido epitelial cervical contido em cada lâmina, foi selecionada a área padronizada citada (Figuras 1 e 2).

Posteriormente, foram ainda tabulados os dados referentes à lesão do colo uterino e análise do número de núcleos marcados positivamente pela S-100 na área da lesão avaliada.

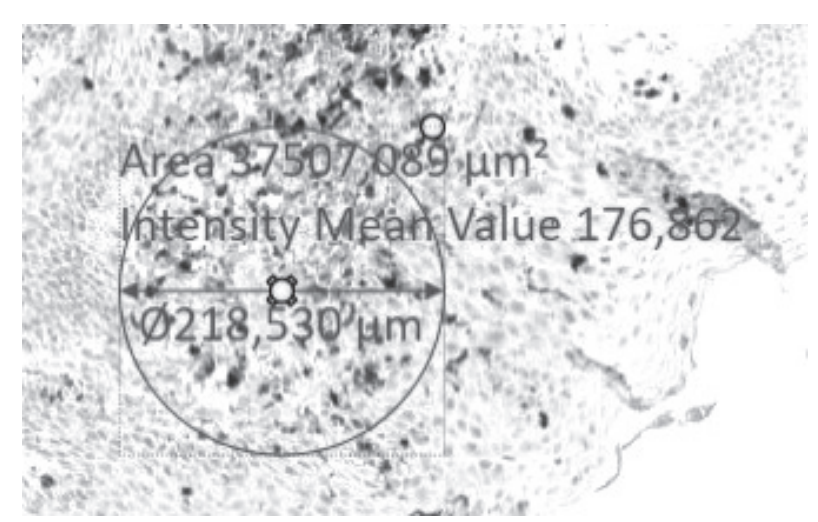

Figura 1. Células de Langerhans marcadas positivamente pela S-100

Nota: Células de Langerhans marcadas positivamente pela S-100 dentro da área circular delimitada. Detalhe da positividade da S-100 em núcleo de células de Langerhans demonstrando marcação nuclear forte (castanho). Aumento de 50\% no programa Zen 2.3 Lite $^{\circledast}$. 


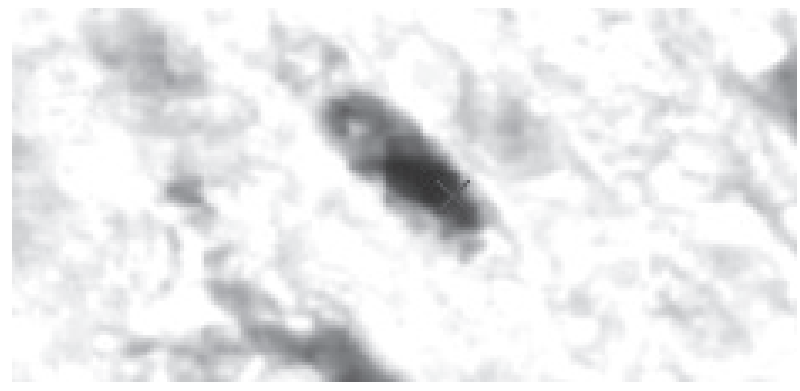

Figura 2. Célula considerada como positiva para contagem corada pela $\mathrm{S}-100$

Nota: Célula considerada marcada positivamente para o estudo.

Os dados foram analisados por testes estatísticos paramétricos (média, mediana e desvio-padrão) e não paramétricos (teste de Kruskal-Wallis) e, para testar a significância de diferenças observadas nas proporçóes das variáveis categóricas, foi considerado estatisticamente significativo um valor de $\mathrm{p}<0,05$.

Entre os fatores de exclusão, foram consideradas idade inferior a 18 anos; peças sem concordância com o laudo original de sua biópsia após a revisão dos diagnósticos; peças em que o bloco de parafina não estava disponível; e peças nas quais, após a confecção das lâminas, não foi encontrado tecido epitelial cervical na análise.

Todo o material ficou sob a responsabilidade dos próprios pesquisadores, com a garantia de manutenção do sigilo e confidencialidade. O projeto de pesquisa foi aprovado pelo Comitê de Ética em Pesquisa da Sociedade Evangélica Beneficente (CEP/SEB) sob o parecer número 1.852.973.

\section{RESULTADOS}

Foram selecionados 119 casos por meio da análise dos laudos no sistema do Laboratório de Anatomia Patológica do Hospital Universitário Evangélico Mackenzie de Curitiba. A amostra final constou de 40 casos de biópsias do colo uterino obtidas por conização por CAF ou histerectomia, com diagnósticos de cervicite crônica (17 casos), NIC I (13 casos) e III (10 casos).

Em relação às idades, a maior variação foi do grupo controle (cervicite crônica). As idades das pacientes do grupo de cervicite crônica variaram de 24 a 78 anos, com média de 48,82 anos, desvio-padráo de 13,28 anos e mediana de 45 anos. Já as idades das pacientes de NIC I variaram de 20 a 66 anos, com média de 39 anos, desvio-padráo de 14,06 anos e mediana de 33 anos. Por último, o grupo de NIC III teve variação de idade de 23 a 60 anos, média de 35,3 anos, desvio-padrão de 10,49 e mediana de 34,5 anos.
O valor de p obtido pelo teste de Kruskal-Wallis para a variação de idade entre os grupos foi de 0,0027, demonstrando uma diferença estatisticamente significativa de idade entre os três grupos.

No que diz respeito à análise comparativa do número de células em cada grupo, a média, o desvio-padrão e a mediana do número de células por área foram maiores no grupo de cervicite crônica. Já os menores valores desses parâmetros foram encontrados no grupo de NIC III (Tabela 1).

Tabela 1. Comparação entre o número de núcleos marcados

\begin{tabular}{ccccc} 
& Cervicite crônica & NIC I & NIC III \\
\hline Média & 30,82 & 20,38 & 15 \\
Desvio-padrão & 19,68 & 9,76 & 7,37 \\
Mediana & 23 & 20 & 14 \\
\hline
\end{tabular}

Legenda: NIC $=$ neoplasia intraepitelial cervical

Houve uma reduçáo do número de núcleos marcados positivamente na comparação dos dois grupos de NIC em relação ao grupo controle (Tabela 2).

Tabela 2. Comparação entre as médias de núcleos marcados em cada grupo e sua redução comparadas ao grupo controle

\begin{tabular}{cc|c}
\hline & Média & $\begin{array}{c}\text { Redução em comparação } \\
\text { com o grupo controle }\end{array}$ \\
\hline Cervicite crônica & 30,82 & $-44 \%$ \\
NIC I & 20,38 & $-51,33 \%$ \\
NIC III & 15 & \\
\hline
\end{tabular}

Legenda: NIC = neoplasia intraepitelial cervical

Também, em relação ao número de células marcadas positivamente, compararam-se os três grupos utilizando o teste não paramétrico de Kruskal-Wallis e obteve-se um valor de $\mathrm{p}$ significativo $(\mathrm{p}=0,0442)$.

Em comparação também com o teste de Kruskal-Wallis, somente no grupo NIC I com o controle não se encontrou diferença estatística significativa $(\mathrm{p}=0,1805)$. Já na análise da diferença do grupo de NIC III com o controle, obteve-se um valor de $\mathrm{p}$ significativo $(\mathrm{p}=0,0209)$.

\section{DISCUSSÃO}

No presente estudo, avaliaram-se 40 casos de cervicite crônica, NIC I e NICIII, procurando quantificar o número de células de Langerhans em cada uma dessas lesôes por meio de imuno-histoquímica.

Vários cuidados foram tomados para aumentar a confiabilidade dos resultados e evitar distorçóes, padronizando a contagem das células de Langerhans e respeitando critérios de exclusão. 
Quanto ao número de células de Langerhans, observou-se uma diminuição mais acentuada em pacientes com NIC III e menos acentuada em pacientes com NIC I, usando pacientes com cervicite crônica como grupo controle.

Teorias como estudos revisados por Southern e Herington sugerem que a diminuição das células de Langerhans seria um defeito na imunidade local do colo uterino, causado por alteraçóes de vigilância imunológica somadas à agresão epitelial pelo $\mathrm{HPV}^{10}$. $\mathrm{O}$ própio $\mathrm{HPV}$ seria capaz de provocar uma imunodeficiência adquirida que favoreceria sua persistência no tecido. Em outras palavras, a persistência do HPV dependeria da sua capacidade de diminuir as células de Langerhans ${ }^{11,12}$. O resultado encontrado de diminuição da quantidade das células de Langerhans, conforme a neoplasia intraepitelial cervical surge (diminuição em pacientes com NIC I e III) e progride (diminuição mais acentuada em NIC III), é favorável à teoria da imunodeficiência causada pelo HPV, que permite sua ação neoplásica.

Porém, outros autores relatam um aumento no número de células de Langerhans em pacientes acometidas por NIC, o que poderia ser em razão de uma resposta imune específica direcionada contra células em transformaçáo neoplásica; ou seja, as células de Langerhans seriam uma resposta imune do organismo ao fenômeno de carcinogênese ${ }^{11}$. Nossos dados divergem dos dados encontrados por Welkovic ${ }^{11}$, que mostram número maior de células de Langerhans em mulheres com lesão de alto grau quando comparado à lesão de baixo grau, utilizando também a S-100. O autor relata que, com a NIC presente, houve aumento progressivo da densidade de células de Langerhans conforme a gravidade da lesão, porém sem resultados estatisticamente significativos. No presente estudo, não se observou aumento da quantidade das células de Langerhans contadas em pacientes com NIC I e III e nem outros sinais de possível resposta imune, como, por exemplo, infiltrado linfocitário importante na área acometida.

Essa discrepância de resultados na literatura pode ocorrer pela dificuldade em selecionar com precisão o local da biópsia no colo uterino, além da diversidade de estágios apresentados por uma infecção por HPV, uso de marcadores diferentes entre os estudos e uso de metodologias diversas 5 . Pode se pensar na diminuição da quantidade de células de Langerhans como sendo um requisito inicial do HPV para o desenvolvimento de seus efeitos oncogênicos. Após a instalação da NIC, pode haver estímulo à produçáo de mais células de Langerhans por migração, proliferação e retenção ${ }^{13}$. Assim, a fase de progressão da NIC e da infecção pelo HPV em que a biópsia é coletada pode também ser um fator de causa de discrepâncias.
Em sua análise, Jimenez-flores et al. ${ }^{5}$ usam a técnica de lençol, que consiste em separar o epitélio do estroma por ação enzimática para poder avaliar melhor as células dendríticas epiteliais. Assim, o autor também encontra uma reduçáo de aproximadamente $50 \%$ no número de células de Langerhans marcadas por Langerina nas amostras de epitélio cervical com NIC I induzido pelo $\mathrm{HPV}$ quando comparadas a amostras negativas para HPV. Isso indica que uma técnica mais precisa para análise das células de Langerhans do epitélio está em conssonância com a teoria da diminuição dessas células na NIC.

A escolha do marcador pode ser um fator determinante no resultado: um estudo de Camargos et al. ${ }^{14}$ mostrou que o número de células de Langerhans positivas por Langerina foi maior em epitélio normal quando comparado com o epitélio acometido por NIC I. Já quando usada a S-100, o número de células de Langerhans foi maior no epitélio acometido por NIC I do que no epitélio normal. No mesmo estudo, com ambos os marcadores, se observou uma redução no número de células de Langerhans em epitélio com NIC III quando comparado ao NIC II, indicando que o fator severidade na neoplasia seria determinante na diminuição dessas células. O que está de acordo com nossos achados.

Connor et al. ${ }^{15}$ sugerem que estudos que usaram a S-100 como marcador de células de Langerhans mostraram diminuição na sua quantidade, enquanto outros estudos que utilizaram outros marcadores como o CD1 não demostraram essa correlação, postulando que a diminuição encontrada nos estudo com S-100 pode ser resultado de um defeito na expressão dessa proteína nessas células.

Ainda, a correlação entre sistema imune e carcinogênese é capaz de mudar a perspectiva do tratamento oncológico, uma vez que a açáo do sistema imune, novas terapias, como imunoterapia, estimuladores da imunidade local e vacinação profilática, se tornam relevantes ${ }^{14}$. Sendo assim, justifica-se a importância da teoria relacionando a imunidade local com o desenvolvimento de uma possível neoplasia, pois novos tratamentos podem ser desenvolvidos.

\section{CONCLUSÃO}

Em relação ao número de núcleos marcados, concluiuse que há diferença significativa da quantidade de células de Langerhans entre os grupos ( $\mathrm{p}=0,0442)$, logo notouse uma reduçáo das células de Langerhans conforme aumentou o grau da neoplasia intraepitelial cervical.

A quantidade de células de Langerhans está diminuída em lesôes do tipo NIC III em comparação a cervicites crônicas ( $\mathrm{p}=0,0209)$ quando quantificada pelo marcador 
S-100. Novos estudos com diferentes marcadores poderiam enriquecer a discussão.

No entanto, não houve redução significativa de células na comparação entre NIC I e cervicite crônica $(\mathrm{p}=0,1805)$, indicando que a diminuição das células de Langerhans está relacionada à progressão para lesôes de alto grau apenas.

\section{CONTRIBUIÇÕES}

Luiz Martins Collaço contribuiu substancialmente para a concepçáo e o delineamento do estudo, revisão crítica relevante do conteúdo intelectual e aprovação final da versão a ser publicada. Júlia Tavares Lopes e Marcella Castro contribuíram substancialmente para a coleta de dados, análise e interpretação dos dados, redação do artigo e aprovação final da versão a ser publicada.

\section{AGRADECIMENTOS}

À Faculdade Evangélica do Paraná, ao seu corpo docente, a funcionários e colaboradores, por nos proporcionarem a estrutura, material didático de apoio, acesso aos laboratórios essenciais para o desenvolvimento do estudo e pela bolsa institucional de fomento à pesquisa. Ao Hospital Universitário Evangélico Mackenzie de Curitiba, especialmente ao serviço de Anatomia Patológica e aos seus funcionários, por fornecerem material de pesquisa e nos apoiar na coleta de dados. Ao Centro de Patologia de Curitiba pela confecção das lâminas, da imuno-histoquímica e por nos receber. E ao Laboratório de Patologia Experimental da Pontifícia Universidade Católica do Paraná (PUC-PR), por emprestar o aparelho Axio Scan.Z1 e o programa Zen 2.3 Lite $^{\circledR}$, e pelo auxílio na análise das lâminas.

\section{DECLARAÇÃO DE CONFLITO DE INTERESSES}

Nada a declarar.

\section{FONTES DE FINANCIAMENTO}

Bolsa Institucional da Faculdade Evangélica Mackenzie do Paraná.

\section{REFERÊNCIAS}

1. Boulet GA, Horvath CA, Berghmans S, et al. Human papillomavirus in cervical cancer screening: important role as biomarker. Cancer Epidemiol Biomarkers Prev. 2008;17(4):810-7. doi: http://dx.doi.org/10.1158/10559965.EPI-07-2865

2. Sousa AMV, Teixeira CCA, Medeiros SS, et al. Mortalidade por câncer do colo do útero no estado do Rio Grande do Norte, Brasil, 1996-2010: tendência e projeçôes até 2030. Epidemiol Serv Saúde. 2016;25(2):311-22. doi: http://dx.doi.org/10.5123/s1679-49742016000200010

3. Hernández-Ramirez LF, Cardona-Arias JA. Lesiones intraepiteliales, inflamación y atipias escamosas cérvicouterinas en mujeres de un municipio de Antioquia, Colombia, 2014. Médicas UIS. 2016;29(1):29-36. doi: http://dx.doi.org/10.18273/revmed.v29n1-2016003

4. Teles CCGD. Estudo epidemiológico de mulheres com lesóes precursoras para câncer do colo uterino na região Sudoeste de Mato Grosso. [dissertação na Internet]. Brasília, DF: Universidade de Brasília; 2010. [acesso 2017 set. 25]. Disponível em: http://repositorio.unb.br/ handle/10482/7731

5. Jimenez-Flores R, Mendez-Cruz R, Ojeda-Ortiz J, et al. High-risk human papilloma virus infection decreases the frequency of dendritic Langerhans' cells in the human female genital tract. Immunology. 2006;117(2):220-228. doi: http://dx.doi.org/10.1111/ j.1365-2567.2005.02282.x

6. Alves DB, Tozetti IA, Gatto FA, et al. Linfócitos CD4, CD8 e células NK no estroma da cérvice uterina de mulheres infectadas pelo papilomavírus humano. Rev Soc Bras Med Trop. 2010;43(4):425-29. doi: http://dx.doi. org/10.1590/S0037-86822010000400018

7. Silva C, Almeida ECS, Côbo EC, et al. A retrospective study on cervical intraepithelial lesions of low-grade and undetermined significance: evolution, associated factors and cytohistological correlation. São Paulo Med J. 2014;132(2):92-96. doi: http://dx.doi. org/10.1590/1516-3180.2014.1322579

8. Kalinski P, Giermasz A, Nakamura Y, et al. Helper role of NK cells during the induction of anticancer responses by dendritic cells. Mol Immunol. 2005;42(4):535-539. doi: http://dx.doi.org/10.1016/j.molimm.2004.07.038

9. Nadal SR, Calore EE, Cruz SHA, et al. Comparação das contagens das células de Langerhans de tecidos contendo carcinoma anal em doentes com e sem infecção pelo HIV. Rev Bras Coloproctol. 2006;26(3):269-274. doi: http:// dx.doi.org/10.1590/S0101-98802006000300006

10. Southern SA, Herrington, CS. Molecular events in uterine cervical cancer. Sex Transm Infect. 1998;74(2);101-9. doi: http://dx.doi.org/10.1136/sti.74.2.101

11. Welkovic S. Células de Langerhans no colo uterino de mulheres hiv soropositivas com neoplasia intraepitelial cervical. [tese na Internet] Recife, PE: Universidade Federal de Pernanbuco; 2007. [acesso 2017 set. 28]. Disponível em: https://repositorio.ufpe.br/ handle/123456789/7333

12. Carvalho MOO. Identificação da presença de células de Langerhans e a ativação de linfócitos $\mathrm{T}$ nos diferentes estágios das lesôes do colo uterino associada à infecção causada pelo vírus do papiloma humano. [tese na Internet]. Rio de Janeiro: Instituto Nacional de 
Infectologia Evandro Chagas, Fundação Oswaldo Cruz; 2016. [acesso 2017 out. 2]. Disponível em: https://www. arca.fiocruz.br/handle/icict/26515

13. Caorsi I, Figueroa CD. Langerhans' cell density in the normal exocervical epithelium and in the cervical intraepithelial neoplasia. Br J Obst Gynaecol. 1986;93(9):993-8. doi: http://dx.doi. org/10.1111/j.1471-0528.1986.tb08022.x

14. Camargos DS, Tafuri A, Fernandes PA, et al. Langerhans cells ascertaining in cervical tissues obtained from women with cervical intraepithelial neoplasia. Reprod Syst Sex Disord. 2017;6(1):203. doi: http://dx.doi. org/10.4172/2161-038X.1000203

15. Connor JP, Ferrer K, Kane JP, et al. Evaluation of Langerhans' cells in the cervical epithelium of women with cervical intraepithelial neoplasia. Gynecol Oncol. 1999;75(1):130-5. doi: http://dx.doi.org/10.1006/ gyno.1999.5559 